\title{
Experimental Evaluation of the Impact of Gadolinium Orthovanadate GdV04:Eu3+ Nanoparticles on the Carrageenan-Induced Intestinal Inflammation
}

\author{
Anton S. Tkachenko ${ }^{1, *}$, Galina I. Gubina-Vakulyck², Vladimir K. Klochkov³, Nataliya S. Kavok³, \\ Anatolii I. Onishchenko ${ }^{1}$, Tatyana V. Gorbach ${ }^{1}$, Oksana A. Nakonechna ${ }^{1}$
}

\begin{abstract}
Aim: To evaluate the effects of orally administered gadolinium orthovanadate $\mathrm{GdVO}_{4}$ : $\mathrm{Eu}^{3+}$ nanoparticles (VNPs) on the course of chronic carrageenan-induced intestinal inflammation.

Methods: Samples of small intestinal tissue were collected from four groups of rats (intact, after administration of VNPs, with carrageenaninduced intestinal inflammation, with carrageenan-induced intestinal inflammation orally exposed to VNPs) to assess the intestinal morphology and HSP90 a expression. Levels of seromucoid, C-reactive protein, TNF- $a$, IL-1 $\beta$ and IL-10 were determined in blood serum. Results: Oral exposure to VNPs was associated with neither elevation of inflammation markers in blood serum nor HSP90a overexpression in the small intestine, i.e. no toxic effects of VNPs were observed. Carrageenan-induced intestinal inflammation was accompanied by higher levels of TNF- $\alpha$ and IL-1 $\beta$, as well as HSP90 a upregulation in the intestinal mucosa, compared with controls. Administration of VNPs to rats with enteritis did not lead to statistically significant changes in concentrations of circulating pro-inflammatory cytokines with the trend towards their increase.

Conclusion: No adverse effects were observed in rats orally exposed to VNPs at a dose of $20 \mu \mathrm{g} / \mathrm{kg}$ during two weeks. Using the experimental model of carrageenan-induced enteritis, it was demonstrated that VNPs at the dose used in our study did not affect the course of intestinal inflammation.
\end{abstract}

\section{KEYWORDS}

nanoparticles; intestinal inflammation; HSP90a; rats; carrageenan

\section{AUTHOR AFFILIATION}

${ }^{1}$ Department of Biochemistry, Kharkiv National Medical University, Kharkiv, Ukraine

${ }^{2}$ Department of Pathological Anatomy, Kharkiv National Medical University, Kharkiv, Ukraine

${ }^{3}$ Institute for Scintillation Materials National Academy of Sciences of Ukraine, Kharkiv, Ukraine

${ }^{*}$ Corresponding author: Department of Biochemistry, Kharkiv National Medical University; Nauky ave, 4, 61022, Kharkiv, Ukraine; e-mail: antontkachenko555@gmail.com

Received: 27 June 2019

Accepted: 8 January 2020

Published online: 18 May 2020

Acta Medica (Hradec Králové) 2020; 63(1): 18-24

https://doi.org/10.14712/18059694.2020.11

(c) 2020 The Authors. This is an open-access article distributed under the terms of the Creative Commons Attribution License (http://creativecommons.org/licenses/by/4.0), which permits unrestricted use, distribution, and reproduction in any medium, provided the original author and source are credited. 


\section{INTRODUCTION}

Inflammatory bowel disease (IBD) is characterized by a chronic intestinal inflammation and includes two subtypes: Crohn's disease (CD) and ulcerative colitis (UC) (1). In CD, the inflammation is transmural and may affect the entire gut, whereas in UC it is mainly limited to the mucosal layer of the large intestine (2). IBD is a multifaceted disease whose development is associated with complex interactions between genetic and environmental factors, including features of intestinal microbiota, abnormalities of the innate immune system, dietary habits, etc. (3). Its conventional treatment includes 5-aminosalicylate, glucocorticoid drugs, methotraxate, azathioprine, and anti-tumor necrosis factor (TNF) agents such as infliximab, adalimumab, golimumab. Furthermore, IL-12/23 antagonists (ustekinumab), inhibitors of intestinal lymphocyte trafficking (vedolizumab, a monoclonal antibody to the a $4 \beta 7$ integrin), and small molecule inhibitors of Janus kinases, including tofacitinib, are currently available in the market (4-8). Nevertheless, the development of novel therapeutic agents for the treatment of IBD remains of huge importance, since the current first-line anti-TNF treatment may be ineffective or the intolerance to anti-TNF agents can emerge in patients (9).

There is strong evidence that IBD is accompanied by the excessive generation of reactive oxygen species (ROS) and subsequent development of oxidative stress $(10,11)$. Overproduction of ROS in IBD results in oxidative damage to macromolecules (lipid peroxidation and protein oxidative modification), loss of cell membrane integrity, low ATP production by mitochondria, apoptosis, etc. (10, 12). This fact substantiates the search for novel, effective antioxidant-based agents for the treatment of IBD (13). In particular, the therapeutic potential of nanoparticles with antioxidant properties has been studied for decades. Converging lines of evidence indicate that they act as ROS scavengers $(14,15)$. It has been reported that gadolinium orthovanadate $\mathrm{GdVO}_{4}: \mathrm{Eu}^{3+}$ nanoparticles (VNPs) can scavenge free radicals in vitro (16). However, little is known about the therapeutic action of VNPs in vivo. To assess the therapeutic potential of VNPs, we have chosen the already characterized experimental model of carrageenan-induced intestinal inflammation (17-19).

The aim of our research was to study the impact of orally administered VNPs on the course of carrageenan-induced intestinal inflammation.

\section{MATERIALS AND METHODS}

\section{DESIGN OF THE STUDY, CHARACTERISTICS OF ANIMALS AND GROUPS}

Fifty female WAG rats weighing $160-190 \mathrm{~g}$ were provided by the vivarium of Kharkiv National Medical University. They were randomly subdivided into five equal groups ( $\mathrm{n}=10$ ). Carrageenan-induced intestinal inflammation was induced in the rats from groups A and B. The animals from group B were orally administered a water solution of VNPs at a dose of $20 \mu \mathrm{g} / \mathrm{kg}$ of weight against the back- ground of intestinal inflammation. Group $C$ included the intact animals fed on a standard diet and obtained a solution of VNPs at a dose of $20 \mu \mathrm{g} / \mathrm{kg}$ of weight. Groups $\mathrm{D}_{1}$ and $\mathrm{D}_{2}$ served as controls and consisted of intact rats. The rats were housed in cages. They were maintained in standard laboratory conditions at room temperature $\left(24 \pm 2{ }^{\circ} \mathrm{C}\right)$. Access to food was free. All the animals were sacrificed. Blood samples were collected to prepare serum for evaluating the systemic levels of inflammation markers. Furthermore, fragments of small intestine were sampled for immunohistochemical studies.

\section{CHARACTERISTICS OF NANOPARTICLES}

The synthesis of $\mathrm{GdVO}_{4}: \mathrm{Eu}^{3+}$ nanoparticle water colloidal solution was carried out in accordance with the method reported earlier (21). Briefly, $10 \mathrm{~mL}$ of aqueous solution of rare-earth chlorides $(0.01 \mathrm{~mol} / \mathrm{L})$ was mixed with $8 \mathrm{~mL}$ of ethylenediaminetetraacetic acid disodium salt (EDTA $2 \mathrm{Na}$ ) solution $(0.01 \mathrm{~mol} / \mathrm{L})$. It was followed by the addition of $8 \mathrm{~mL} \mathrm{Na} \mathrm{VO}_{4}(0.01 \mathrm{~mol} / \mathrm{L})$ to the solution obtained dropwise $(\mathrm{pH}=13)$. The mixture was intensively stirred by a magnetic stirrer until yellowish transparent solution was formed.

The colorless transparent solution obtained as a result scattered light under the side illumination (Tindal cone). The solution was cooled and dialyzed against water for $24 \mathrm{~h}$ to remove the excess of ions. A dialysis membrane with a molecular weight cutoff of $12 \mathrm{kDa}$ with a pore size of approximately $2.5 \mathrm{~nm}$ was used. The composition of spindle-like nanoparticles $-\mathrm{Gd}_{(0,9)} \mathrm{Eu}_{(0,1)} \mathrm{VO}_{4}$ - with average size of $8 \times 25 \mathrm{~nm}$ was formed (Figure 1).

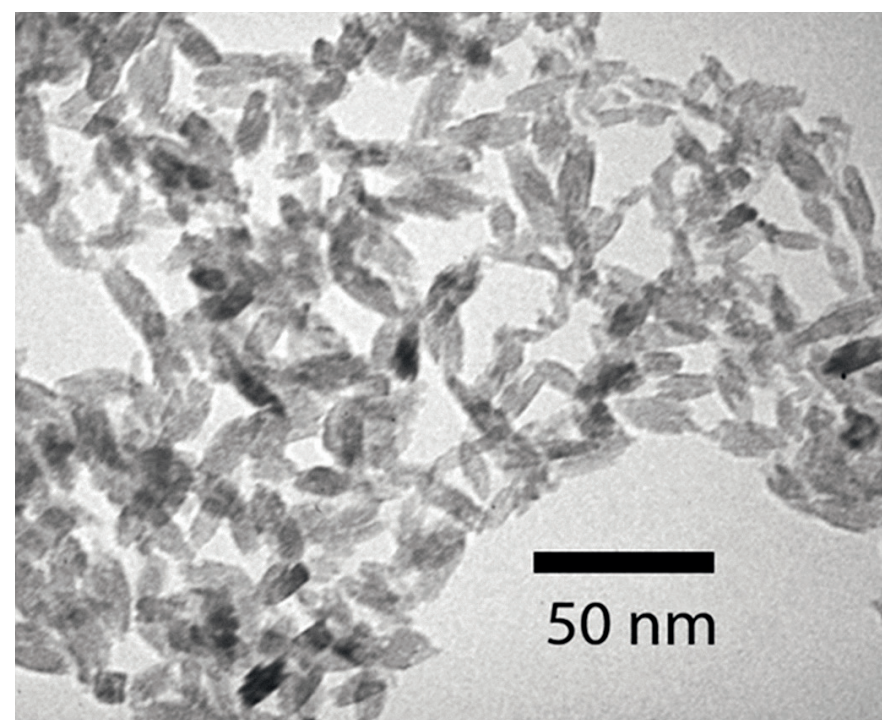

Fig. 1 TEM images of nanoparticles in colloidal solutions. VNPs with an average size of $8 \times 25 \mathrm{~nm}$ used in this study are shown.

\section{CARRAGEENAN-INDUCED INTESTINAL INFLAMMATION MODEL}

Intestinal inflammation in the rats from group $A$ and group $\mathrm{B}$ was induced by the daily oral administration of $\mathrm{k}$-carrageenan-containing $1 \%$ processed Eucheuma seaweed (PES) in drinking water (140 mg per kg of weight) during 4 months. In addition to carrageenan, PES contained less 
than $15 \%$ of algal cellulose. The solution was prepared at least $24 \mathrm{~h}$ prior to its administration and stored at low temperature $\left(2^{\circ} \mathrm{C}\right)$.

Development of intestinal inflammation was confirmed in each animal from groups A and B using routine histological staining techniques (hematoxylin and eosin staining, PAS reaction, and hallocyanine-chrome alum Einarsson's stain).

\section{DETERMINATION OF SYSTEMIC LEVELS OF INFLAMMATORY AND ANTI-INFLAMMATORY BIOMARKERS}

Systemic levels of pro-inflammatory cytokines TNF- $\alpha$ and IL-1 $\beta$ were assessed by commercially available ELISA kits purchased from eBioScience (Austria). The procedures were done strictly in accordance with manufacturers' instructions. Concentrations of TNF- $\alpha$, IL- $1 \beta$ and IL-10 in blood serum were expressed in $\mathrm{pg} / \mathrm{ml}$. ELISA method was also used to assess the levels of anti-inflammatory cytokine IL-10 in blood serum of animals (eBioScience ELISA kit).

Furthermore, the levels of inflammatory markers such as seromucoid and C-reactive protein were determined in blood serum of rats from groups $C$ and $D_{2}$ by routine techniques. Seromucoid and C-reactive protein levels were assessed using commercially available kits manufactured by Filicit-Diagnostika (Ukraine). Seromucoid levels were expressed in units of the Shank-Hoagland scale (SH units), whereas the content of C-reactive protein in blood serum was represented in $\mathrm{mg} / \mathrm{L}$. In addition, the content of middle molecules was determined in blood serum of animals from groups $C$ and $D_{2}$ by the Gabrielyan's method to evaluate the severity of endogenous intoxication (22). Tricholoacetic acid was added to serum. Then the mixture was centrifuged during 20 minutes at $3000 \mathrm{rpm}$. After centrifugation the samples were 10 -fold diluted with distilled water. After stirring, the measurement was performed at $\lambda=254 \mathrm{~nm}$ and at $\lambda=280 \mathrm{~nm}$. The $280 \mathrm{~nm} / 254 \mathrm{~nm}$ absorbance ratio was calculated. Concentrations of middle molecules were expressed in standard units.

\section{IMMUNOHISTOCHEMICAL EVALUATION OF HSP9Oa EXPRESSION IN THE SMALL INTESTINE}

Tissue samples of small intestine were fixed in a $10 \%$ formalin solution. Then paraffin-embedded tissues were used to obtain $4-\mu \mathrm{m}$-thick sections, which were immunostained using commercially available mouse monoclonal antibodies to HSP90a purchased from Thermo Fischer Scientific (USA). After incubation with the primary antibodies, the microslides were treated with an anti-(mouse IgG)-horseradish peroxidase conjugate. Visualization was carried out using $3,3^{\prime}$-diaminobenzidine (DAB) staining. The presence of brown coloration indicated the positive reaction.

\section{BIOETHICS}

All the experimental procedures were performed following the guidelines of EU Directive 2010/63/EU on the protection of animals used for scientific purposes, which is based on the Council of Europe Convection for the Protection of Vertebrate Animals used for Experimental and other Scientific Purposes (ETS123).

\section{STATISTICAL ANALYSIS}

Numerical data were analyzed using the Kruskal-Wallis ANOVA test if three independent parameters were compared. It was followed by the Dunn's multiple comparison post-hoc test. Two independent groups of variables were compared by a non-parametric Mann-Whitney U test. It was selected based on the outcome of the Shapiro-Wilk and Kolmogorov-Smirnov normality tests. Differences were considered statistically significant at $p<0.05$. The data obtained in our research were analyzed with GraphPad Prism 5.0 (GraphPad software, USA).

\section{RESULTS}

To assess the toxicity and pro-inflammatory potential of VNPs, we determined the levels IL-1 $\beta$, middle molecules, C-reactive protein, and seromucoid in blood serum of rats from group $C$ and compared them with the corresponding parameters of animals from the control group $D_{2}$. The concentrations of pro-inflammatory IL-1 $\beta$, middle molecules and acute phase proteins (seromucoid and C-reactive protein) in blood serum of rats orally exposed to the solution of VNPs were statistically insignificantly $(p>0.05)$ higher than in the animals from the control group $\mathrm{D}_{2}$ (Table 1 ).

Morphological studies of small intestine in rats from both control groups demonstrated that the epithelial layer of villi was intact. Epithelial cells at the top of intestinal villi regenerated well. No significant leukocyte infiltrate was found (Figures 2, 3).

Immunolabelling allowed us to find out that HSP90a was primarily expressed in the cytosol. HSP90a-positive cells were detected both in the epithelial lining and intestinal glands. Immunostaining was also observed in the lami-

Tab. 1 Evaluation of orally administered $\mathrm{GdVO}_{4}$ nanoparticle toxicity (Me (IQR)).

\begin{tabular}{|c|c|c|c|}
\hline Groups of animals & \multirow{2}{*}{$\begin{array}{l}\text { Group } D_{2} \\
\text { (intact animals, } n=10 \text { ) }\end{array}$} & \multirow{2}{*}{$\begin{array}{l}\text { Group C } \\
\text { (rats orally exposed to VNPs, } n=10 \text { ) }\end{array}$} & \multirow[t]{2}{*}{$p$ value } \\
\hline Blood serum parameters (units) & & & \\
\hline $\mathrm{IL}-1 \beta(\mathrm{pg} / \mathrm{ml})$ & $62.32(47.23 ; 69.89)$ & $64.21(55.36 ; 75.54)$ & 0.529 \\
\hline C-reactive protein $(\mathrm{mg} / \mathrm{L})$ & $1.12(0.97 ; 1.18)$ & $1.20(1.09 ; 1.30)$ & 0.059 \\
\hline Seromucoid (SH units) & $3.00(2.88 ; 3.35)$ & $3.45(3.10 ; 3.68)$ & 0.129 \\
\hline Middle molecules (standard units) & $0.080(0.074 ; 0.084)$ & $0.083(0.079 ; 0.088)$ & 0.172 \\
\hline
\end{tabular}

Note: Differences were considered statistically significant at $p<0.05$ 


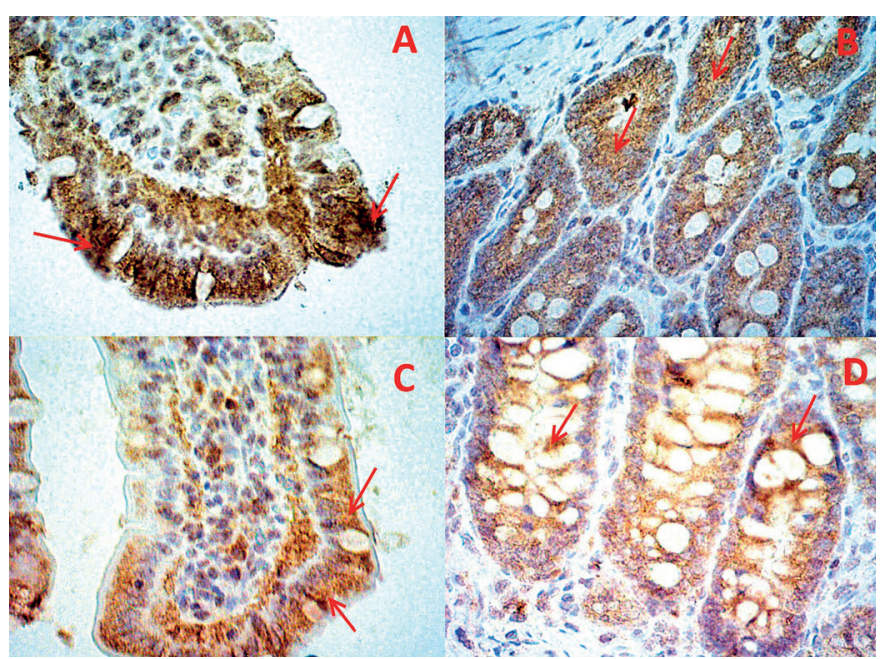

Fig. 2 Small intestinal mucosa immunostaining. A) Control group $D_{2}$. Positive HSP90a staining is found in the epithelial lining and the lamina propria (marked with red arrows). Immunohistochemical reaction with antibodies to HSP90a. $\times 400$. B) Control group $D_{2}$. HSP90a-positive cells are revealed in the intestinal glands (marked with red arrows). Immunohistochemical reaction with antibodies to HSP90a. $\times 100$. C). Group C. The HSP90a expression pattern after the oral administration of $\mathrm{GdVO}_{4}$ nanoparticles does not differ from the control group $\mathrm{D}_{2}$ HSP9Oa is moderately expressed in the lamina propria and epitheliocytes (marked with red arrows). Immunohistochemical reaction with antibodies to HSP90a. $\times 400$. D) Group C. HSP90a is expressed at the moderate level in the intestinal glands (marked with red arrows). No HSP9Oa overexpression was found compared with the control animals. Immunohistochemical reaction with antibodies to HSP90a. $\times 100$.

na propria. However, the amount of HSP90a-stained cells both in the lamina propria and intestinal epitheliocytes was moderate (Figures 2, 3).

Evaluation of the impact of VNPs on small intestine morphology and HSP90a expression showed that the oral exposure of rats to nanoparticles affected neither histological features of the small intestine nor the chaperone expression. No signs of intestinal inflammation were revealed in rats from group C. Epithelium and villi were not damaged. The leukocyte infiltrate was as non-abundant as in both control groups $\mathrm{D}_{1}$ and $\mathrm{D}_{2}$ (Figure 2).

In this study, we observed almost the same pattern of HSP90 a expression in rats orally exposed to VNPs as in groups $\mathrm{D}_{1}$ and $\mathrm{D}_{2}$. Qualitative analysis indicated that

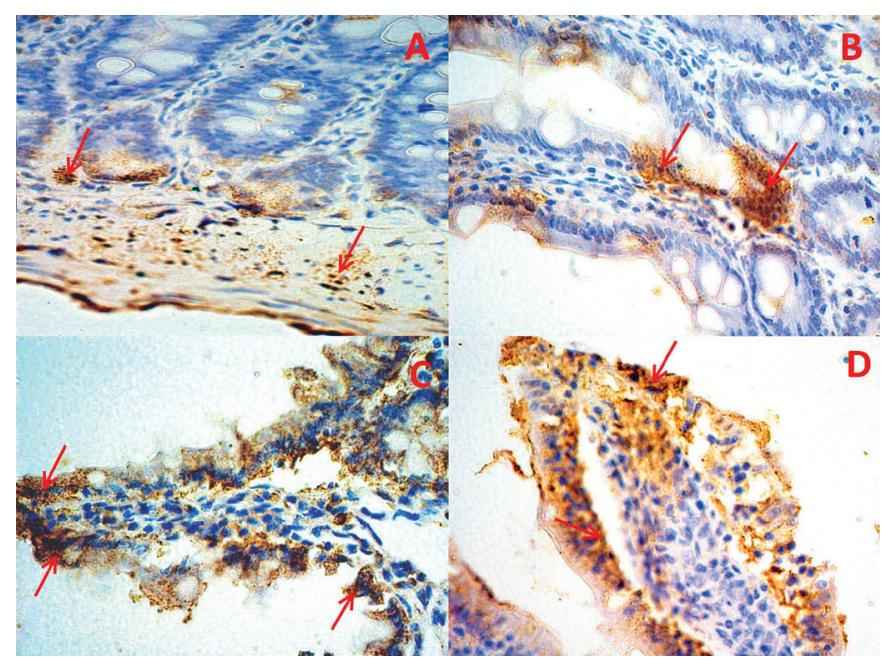

Fig. 3 Small intestinal mucosa immunostaining. A) Control group $D_{1}$. HSP90a staining is weak and the amount of HSP90a-labelled cells is limited. HSP90a-positive cells are found both in the lamina propria and glands (marked with red arrows). Immunohistochemical reaction with anti-bodies to HSP90a. $\times 100$. B) Control group $D_{1}$. Many cells are HSP90a-negative. The foci of HSP90a positive immunostaining are shown (marked with red arrows). Immunohistochemical reaction with antibodies to HSP90a. $\times 100$. C). Group A. A more pronounced HSP90a expression is found in the lamina propria and epithelial cells against the background of intestinal inflammation compared with the control group (marked with red arrows). Immunohistochemical reaction with antibodies to HSP90a. $\times 100$. D) Group A. HSP90a overexpression is observed in the intestinal villi (marked with red arrows). The amount of HSP9Oa-positive cells is higher than in the control group. Immunohistochemical reaction with antibodies to HSP90a. $\times 100$.

HSP90 a was moderately expressed in the lamina propria, epithelial cells, and glands (Figure 2).

We observed the statistically significant $(p<0.0001$ and $p=0.005$, respectively) 4.1 -fold and 1.8 -fold increase in the concentrations of circulating pro-inflammatory cytokines TNF- $\alpha$ and IL-1 $\beta$ in rats from group A compared with the control group $\mathrm{D}_{1}$ (Table 2 ). The content of anti-inflammatory IL-10 did not differ from controls $(p>0.05)$. Levels of TNF- $\alpha$ and IL- $1 \beta$ in rats with carrageenan-induced inflammation treated with VNPs was higher than in group A. However, the difference was found to be statistically insignificant. Circulating IL-10 levels in animals from group B were statistically insignificantly $(\mathrm{p}>0.05)$ higher than in both group $\mathrm{D}_{1}$ and group $\mathrm{A}$ (Table 2).

Tab. 2 Levels of pro-inflammatory markers in untreated and treated rats with carrageenan-induced intestinal inflammation (Me (IQR)).

\begin{tabular}{|c|c|c|c|}
\hline Blood serum parameters (units) & \multirow[t]{2}{*}{ TNF-a (pg/ml) } & \multirow[t]{2}{*}{ IL-1 $(\mathrm{pg} / \mathrm{ml})$} & \multirow[t]{2}{*}{ IL-10 (pg/ml) } \\
\hline Groups of animals & & & \\
\hline $\begin{array}{l}\text { Group } \mathrm{D}_{1} \\
\text { (intact animals, } \mathrm{n}=10 \text { ) }\end{array}$ & $38.9(33.2 ; 48.4)$ & $52.01(36.17 ; 67.04)$ & $54.2(48.8 ; 64.3)$ \\
\hline $\begin{array}{l}\text { Group A } \\
\text { (rats with carrageenan-induced intestinal inflammation, } n=10 \text { ) }\end{array}$ & $161.2(114.6 ; 236.8)$ & 96.08 (80.89; 118.51) & $53.0(47.7 ; 59.8)$ \\
\hline $\begin{array}{l}\text { Group B } \\
\text { (rats with carrageenan-induced intestinal inflammation treated } \\
\text { with VNPs, } n=10 \text { ) }\end{array}$ & $223.7(112.4 ; 360.4)$ & $\begin{array}{l}140.03 \\
(99.91 ; 180.88)\end{array}$ & $57.6(48.2 ; 72.6)$ \\
\hline$p$ value & $\begin{array}{l}p_{1}<0.0001^{*} \\
p_{2}>0.05\end{array}$ & $\begin{array}{l}p_{1}=0.0005^{*} \\
p_{2}>0.05\end{array}$ & $p=0.719$ \\
\hline
\end{tabular}

Note: Differences were considered statistically significant at $p<0.05\left({ }^{*}\right.$ indicates the statistical significance of differences between two independent variables). $p_{1}$ is the difference between groups $D_{1}$ and $A$, while $p_{2}$ is the difference between groups $A$ and $B$. 


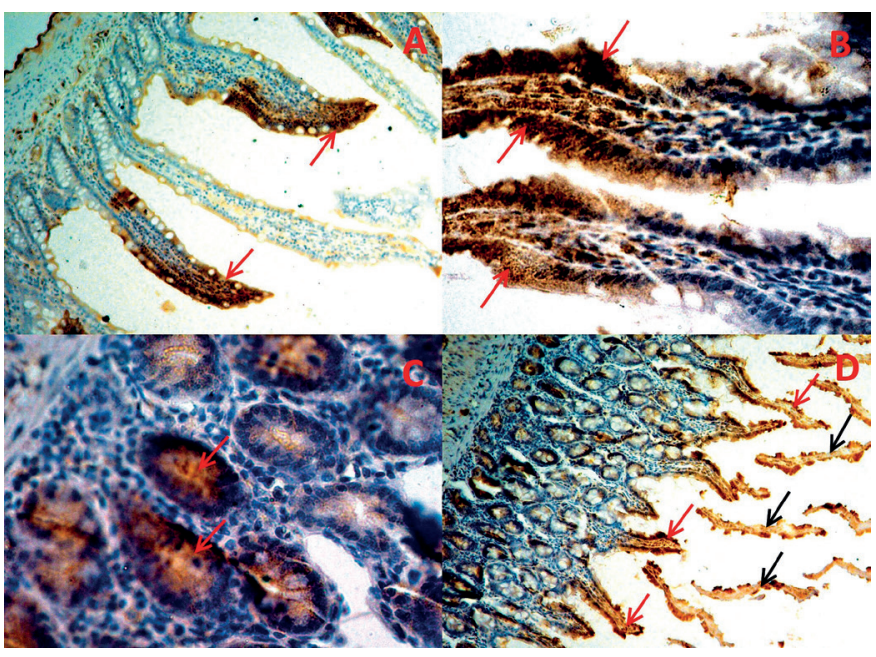

Fig. 4. Small intestinal mucosa immunostaining. Group B. Rats with carrageenan-induced intestinal inflammation treated with $\mathrm{GdVO}_{4}$ nanoparticles A) Strong HSP90a immunostaining is observed at the top of intestinal villi (marked with red arrows). However, the epithelial layer below is preserved. Macrophage infiltration can be seen. Immunohistochemical reaction with antibodies to HSP90a. $\times 100$. B) Very significant HSP90a labeling is found in the intestinal villi against the background of leukocyte infiltration. HSP9Oapositive cells are marked with red arrows. Immunohistochemical reaction with antibodies to HSP90a. $\times 400$. C). Strong HSP90a staining is revealed in the intestinal glands (marked with red arrows). Immunohistochemical reaction with antibodies to HSP90a. $\times 400$. D) Fragments of the destroyed villi with strong HSP90a immunostaining are seen in the small intestinal lumen (marked with red arrows). Furthermore, the strongest HSP90a staining was found at the top of villi (marked with black arrows). Immunohistochemical reaction with antibodies to HSP90a. $\times 100$.

We demonstrated that the oral intake of carrageenan-containing solution by animals from group A resulted in the development of intestinal inflammation, evidenced by the damage to the intestinal villi, especially at their top. Furthermore, the damaged intestinal villi lacked epithelial cells in some regions. The lamina propria both in the villi and at the level of glands was significantly infiltrated with macrophages (Figure 3).

Analysis of HSP90a immunostaining showed that the epithelial cells of villi were strongly labeled. Moreover, the significant HSP9Oa upregulation was detected in glandular epithelial cells, not only at the base of intestinal glands but also above. Both the number of HSP90a-labeled epithelial cells and the intensity of immunostaining were higher in group A compared with controls (Figure 3).

Administration of VNPs against the background of carrageenan-induced inflammation by rats from group $B$ was associated with the leukocyte infiltration with the predominance of macrophages. The infiltration abundance in rats from group B did not differ significantly from group A. In addition, the villi with the undamaged epithelial lining were found. It is interesting to note that some regions of the intestinal wall contained villi with the destroyed tops, while the lower portions of villi were well epithelialized, indicating the rapid regeneration (Figure 4).

Strong HSP90 a staining was primarily observed at the top of villi. However, some villi were either not or weakly immunostained. In some regions, the moderate HSP9Oa expression was revealed.

\section{DISCUSSION}

Nanotechnology has already shown its significant potential in the field of medicine. Biomedical application of nanoparticles seems to be promising therapeutic agents due to their relatively small size and unique characteristics $(23,24)$. Nevertheless, the possibility of administering nanoparticles as drugs raises concerns regarding their adverse effects and probable toxicity. Thus, we evaluated safety and oral exposure risks of VNPs. Our findings indicate that the oral consumption of VNPs during two weeks is not associated with the statistically significant changes in the content of circulating inflammatory markers such as IL- $1 \beta$, seromucoid, and C-reactive proteins. Biochemical data are supported by the results of morphological studies. No morphological signs of intestinal inflammation were found in animals exposed to VNPs. Furthermore, the development of intoxication in response to VNPs oral consumption was not found, evidenced by the absence of middle molecules elevation in blood serum.

We also assessed expression of HSP9Oa, which is a molecular chaperone involved in the regulation of cellular proteostasis promoting protein folding and refolding in response to stress factors (25). It is worth mentioning that HSP9O $\alpha$ is an isoform of the chaperone upregulated in stress conditions, while its $\beta$ form is expressed constitutively (26). It has been reported that HSP90 $\alpha$ is upregulated during inflammation (including the intestinal one) and in response to oxidative stress (27). No changes in its expression confirm the data of biochemical studies and indicate the absence of inflammation in the intestine after the oral consumption of VNPs.

Our biochemical and histological findings suggest that VNPs have no toxic effects when exposed orally at a dose of $20 \mu \mathrm{g} / \mathrm{kg}$ of weight during two weeks. Based on our findings, VNPs cannot be considered pro-inflammatory agents. Such conclusion is consistent with data of studies focused on elucidation of VNP properties and biological effects (28-31).

The next task of our research was to assess the therapeutic potential of VNPs in intestinal inflammation caused by oral consumption of a carrageenan-containing solution. Carrageenans are sulfated hydrocolloids of polysaccharide nature extracted from microalgae and used in food industry as thickeners, stabilizers, and emulsifiers (32). In addition, this food additive can trigger the development of intestinal inflammation as a result of its oral consumption by rats (17-20). The development of inflammation in the rats from group A was confirmed in this study histologically and biochemically. Changes in the blood serum cytokine profile observed in our study indicated the active inflammatory process in the intestine. We believe that elevation of circulating pro-inflammatory TNF- $\alpha$ and IL-1 $\beta$ is mediated, at least partially by ROS, whose overexpression is known to be stimulated by carrageenan (33). In our previous study, we linked HSP90a intestinal overexpression revealed in this study with the development of oxidative stress in carrageenan-induced enteritis as well (17). This overexpression seems to be protective and aim at providing re-folding of damaged protein to promote survival of enterocytes. 
VNPs did not stimulate the synthesis of anti-inflammatory IL-10 and even worsened the imbalance between circulating pro-inflammatory and anti-inflammatory cytokines, albeit the difference was statistically insignificant. Thus, we believe that VNPs at the dose used in our study does not affect the course of inflammation. It is worth noting that that their oral consumption does not lead to the intensification of inflammatory response. Furthermore, the strongest HSP90a immunostaining in animals from group B is observed at the top of intestinal villi and seem to be compensatory. However, this was not sufficient to provide the cell survival and resulted in the reduced viability of cells and activation of cell death. In Figure 4 (D) we can notice such damaged villi alienated from the mucosa in the lumen of small intestine with strong HSP90 a expression. In response to cell death, the regeneration should be activated. And we have managed to find the areas of extensive regeneration of enterocytes at the bottom of villi. We believe that such regeneration may be protective and can be associated with the action of VNPs. Such regions with so intense regeneration were not found in non-treated rats.

\section{CONCLUSION}

Oral exposure to VNPs at a dose of $20 \mu \mathrm{g} / \mathrm{kg}$ of weight by rats during two weeks showed no adverse effects. VNPs neither affect the level of circulating inflammatory markers nor influence the small intestinal morphology. Furthermore, their oral intake was not associated with overexpression of ROS-inducable chaperone HSP90a in the intestinal mucosa. Evaluation of VNP therapeutic potential using an experimental model of carrageenan-induced enteritis demonstrated no significant effects on the course of inflammation. However, HSP90 a overexpression in rats with carrageenan-induced intestinal inflammation treated with VNPs prevailed at the top of villi in a combination with the active proliferation at the bottom.

\section{FUNDING}

The study was not funded in any way.

\section{CONFLICT OF INTEREST}

The authors have no conflict of interest to disclose.

\section{REFERENCES}

1. Kim DH, Cheon JH. Pathogenesis of inflammatory bowel disease and recent advances in biologic therapies. Immune Netw 2017; 17(1): 25-40.

2. Qin X. Why is damage limited to the mucosa in ulcerative colitis but transmural in Crohn's disease?. World J Gastrointest Pathophysiol 2013; 4(3): 63-4.

3. Wawrzyniak M, Scharl M. Genetics and epigenetics of inflammatory bowel disease. Swiss Med Wkly 2018; 148: w14671.

4. Battat R, Dulai PS, Jairath V, Vande Casteele N. A product review of vedolizumab in inflammatory bowel disease. Hum Vaccin Immunother 2019; 15(10): 2482-90.

5. Gomollón F, Dignass A, Annesse V, et al. ECCO: Third European evidence-based consensus on the diagnosis and management of
Crohn's Disease 2016: Part 1: Diagnosis and medical management. J Crohns Colitis 2017; 11(1): 3-25.

6. Harbord M, Eliakim R, Bettenworth D, et al. ECCO. Third European Evidence-based Consensus on Diagnosis and Management of Ulcerative Colitis. Part 2: Current Management. J Crohns Colitis. 2017; 11 (7): 769-84.

7. Lee HS, Park SK, Park DI. Novel treatments for inflammatory bowel disease. Korean J Intern Med 2018; 33(1): 20-7.

8. Hvas CL, Bendix M, Dige A, Dahlerup JF, Agnholt J. Current, experimental, and future treatments in inflammatory bowel disease: a clinical review. Immunopharmacol Immunotoxicol 2018; 40(6): 446-60.

9. Chudy-Onwugaje KO, Christian KE, Farraye FA, Cross RK. A state-ofthe-art review of new and emerging therapies for the treatment of IBD. Inflamm Bowel Dis 2018.

10. Tian T, Wang Z, Zhang J. Pathomechanisms of oxidative stress in inflammatory bowel disease and potential antioxidant therapies. Oxid Med Cell Longev 2017; 2017: 4535194.

11. Aviello G, Knaus UG. ROS in gastrointestinal inflammation: Rescue Or Sabotage?. Br J Pharmacol 2017; 174(12): 1704-18.

12. Guan G, Lan S. Implications of antioxidant systems in inflammatory bowel disease. Biomed Res Int 2018; 2018: 1290179.

13. Moura FA, de Andrade KQ, Dos Santos JCF, Araújo ORP, Goulart MOF. Antioxidant therapy for treatment of inflammatory bowel disease: Does it work? Redox Biol 6: 617-39.

14. Mauricio MD, Guerra-Ojeda S, Marchio P, et al. Nanoparticles in medicine: A focus on vascular oxidative stress. Oxid Med Cell Longev 2018; 2018: 6231482 .

15. Newkirk GM, Wu H, Santana I, Giraldo JP. Catalytic scavenging of plant reactive oxygen species in vivo by anionic cerium oxide nanoparticles. J Vis Exp 2018; (138).

16. Hubenko K, Yefimova S, Tkacheva T, et al. Reactive oxygen species generation in aqueous solutions containing $\mathrm{GdVO}_{4}$ : $\mathrm{Eu}^{3+}$ nanoparticles and their complexes with methylene blue. Nanoscale Res Lett 2018; 13(1): 100 .

17. Tkachenko AS, Onishchenko AI, Gorbach TV, Nakonechna OA, Shekhovtsova EV, Gubina-Vakulyck GI. HSP90a overexpression in small intestinal mucosa and high blood serum levels of HSP70 and 8-isoprostane in carrageenan-induced intestinal inflammation. HVM Bioflux 2019; 11(1): 1-5.

18. Tkachenko AS, Onishchenko AI, Gorbach TV, Gubina-Vakulyck GI. O-6-methylguanine-DNA methyltransferase (MGMT) overexpression in small intestinal mucosa in experimental carrageenan-induced enteritis. Malay J Biochem Mol Biol 2018; 21(3): 77-80.

19. Tkachenko A, Marakushyn D, Kalashnyk I, et al. A study of enterocyte membranes during activation of apoptotic processes in chronic carrageenan-induced gastroenterocolitis. Med Glas (Zenica) 2018; $15(2): 87-92$.

20. Gubina-Vakyulyk GI, Gorbach TV, Tkachenko AS, Tkachenko MO. Damage and regeneration of small intestinal enterocytes under the influence of carrageenan induces chronic enteritis. Comparative Clinical Pathology 2015; 24(6): 1473-7.

21. Klochkov VK, Malyshenko AI, Sedyh OO, Malyukin YuV. Wet-chemical synthesis and characterization of luminescent colloidal nanoparticles: $\mathrm{ReVO}_{4}: \mathrm{Eu}^{3+}(\mathrm{Re}=\mathrm{La}, \mathrm{Gd}, \mathrm{Y})$ with rod-like and spindle-like shape. Functional Materials 2011; 1: 111-5.

22. Gabriyelyan NI, Lipatova VI. Experience of using index of middle molecules in blood to diagnose nephrological diseases among children. Lab Delo 1984; 3: 138-140 (in Russian).

23. Chatterjee S, Kumari RM, Nimesh S. Nanotoxicology: Evaluation of toxicity potential of nanoparticles. In Advances in Nanomedicine for the Delivery of Therapeutic Nucleic Acids, N., Eds.; Elsevier: New York City, NY, USA, 2017; pp. 187-201.

24. Wang M, Lai X, Shao L, Li L. Evaluation of immunoresponses and cytotoxicity from skin exposure to metallic nanoparticles. Int J Nanomedicine 2018; 13: 4445-59.

25. Padmini E, Usha Rani M. Heat-shock protein 90 alpha (HSP90a) modulates signaling pathways towards tolerance of oxidative stress and enhanced survival of hepatocytes of Mugil cephalus. Cell Stress Chaperones $2011 ; 16(4): 411-25$.

26. Zuehlke AD, Beebe K, Neckers L, Prince T. Regulation and function of the human HSP90AA1 gene. Gene 2015; 570(1): 8-16.

27. Grimstad T, Kvivik I, Kvaløy JT, Aabakken L, Omdal R. Heat shock protein 90 and inflammatory activity in newly onset Crohn's disease. Scand J Gastroenterol 2018; 53(12): 1453-8.

28. Karpenko NO, Belkina VN, Klochkov VN et al. Study of orthovanadate nanoparticle toxicity // Achievements and Prospects of Experimental and Clinical Endocrinology (15th Danilevsky Conference), Kharkiv; 2016: 44-45 (in Ukrainian)

29. Mamotyuk EM, Klochkov VK, Grygorova GV, Yefimova SL, Malyukin YuV. Radioprotective effect of $\mathrm{CeO}_{2}$ and $\mathrm{GdEuVO}_{4}$ nanopar- 
ticles in "in vivo" experiments. Nanoscience Advances in CBRN Agents Detection, Information and Energy Security: Springer; 2015: 193-7.

30. Averchenko EA, Kavok NS, Klochkov VK, Malyukin YuV. Chemiluminescent diagnostics of free-radical processes in an abiotic system and in liver cells in the presence of nanoparticles based on rare-earth elements nReVO $\mathrm{Eu}^{3+}(\mathrm{Re}=\mathrm{Gd}, \mathrm{Y}, \mathrm{La})$ and $\mathrm{CeO}_{2}$. Journal of Applied Spectroscopy 2014; 81(5): 827-33.

31. Karpenko NA, Malukin YuV, Koreneva EM et al. The effects of chronic intake of cerium dioxide or gadolinium ortovanadate nanoparticles in aging male rats. Proceedings of the 3rd Int. Conf. "Nanomaterials: Applications and Properties '2013", September 16-21, 2013; Alushta, Ukraine; 2(4): 04NAMB28-1-04NAMB28-4.

32. Saha D, Bhattacharya S. Hydrocolloids as thickening and gelling agents in food: a critical review. J Food Sci Technol 2010; 47(6): 587-97.

33. Barth CR, Funchal GA, Luft C, de Oliveira JR, Porto BN, Donadio MV. Carrageenan-induced inflammation promotes ROS generation and neutrophil extracellular trap formation in a mouse model of peritonitis. Eur J Immunol 2016; 46(4): 964-70. 